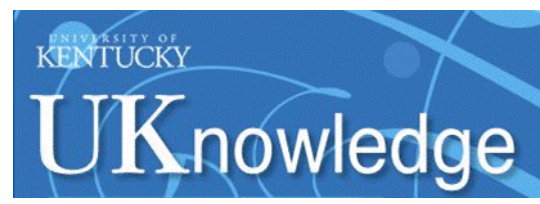

University of Kentucky

UKnowledge

8-17-2013

\title{
Predictors of Online and Offline Sexual Activities and Behaviors Among Adolescents
}

\author{
Anna Ševčíková \\ Masaryk University, Czech Republic \\ Alexander T. Vazsonyi \\ University of Kentucky, vazsonyi@uky.edu \\ Janelle Širůček \\ Masaryk University, Czech Republic \\ Štěpán Konečný \\ Brno University of Technology, Czech Republic
}

Follow this and additional works at: https://uknowledge.uky.edu/psychology_facpub

Part of the Psychology Commons

Right click to open a feedback form in a new tab to let us know how this document benefits you.

\section{Repository Citation}

Ševčíková, Anna; Vazsonyi, Alexander T.; Širůček, Janelle; and Konečný, Štěpán, "Predictors of Online and Offline Sexual Activities and Behaviors Among Adolescents" (2013). Psychology Faculty Publications.

123.

https://uknowledge.uky.edu/psychology_facpub/123

This Article is brought to you for free and open access by the Psychology at UKnowledge. It has been accepted for inclusion in Psychology Faculty Publications by an authorized administrator of UKnowledge. For more information, please contact UKnowledge@lsv.uky.edu. 


\section{Predictors of Online and Offline Sexual Activities and Behaviors Among Adolescents}

Digital Object Identifier (DOI)

http://dx.doi.org/10.1089/cyber.2012.0552

Notes/Citation Information

Published in Cyberpsychology, Behavior, and Social Networking, v. 16, no. 8, p. 618-622.

This is a copy of an article published in the Cyberpsychology, Behavior, and Social Networking (c), 2013, copyright Mary Ann Liebert, Inc.; Cyberpsychology, Behavior, and Social Networking is available online at: http://online.liebertpub.com. 


\title{
Predictors of Online and Offline Sexual Activities and Behaviors Among Adolescents
}

\author{
Anna Ševčíková, PhD, Alexander T. Vazsonyi, $\mathrm{PhD}{ }^{2}$ Jan Širůček, $\mathrm{PhD}^{3}$, and Štěpán Konečný, $\mathrm{PhD}^{4}$
}

\begin{abstract}
Despite the fact that many adolescents spend much time on the Internet, it is unknown who engages in sexually related online activities (SROA) and how these affect adolescent sexual development. The present longitudinal study on 323 adolescents (51.1\% girls) aimed to explore how peer attachment processes predicted both SROA and offline sexual behaviors at the age of 17 , while also considering puberty and prior offline sexual experiences in order to elucidate potential similarities or differences. Findings based on hierarchical, binary logistic regression analyses revealed that SROA were predicted by alienation attachment to peers $(\mathrm{OR}=3.36, p<0.05)$, puberty $(\mathrm{OR}=1.03, p<0.05)$, and prior SROA (OR $=0.56, p<0.001)$, while only previous offline sexual experiences at the age of 15 increased the likelihood of offline sexual behaviors at the age of 17 (OR=6.04, $p<0.001)$. Study findings indicate that the Internet provides an additional context for acquiring sexual experiences during adolescence.
\end{abstract}

\section{Introduction}

I NTERNET USE HAS BECOME AN INTEGRAL PART of adolescent life. In contrast to traditional media, it offers both specific content and the opportunity to interact with others. Its features, in particular anonymity and access to sexual content, make it a unique venue for the exploration of adolescent sexuality. It also reduces the risk of personal or social sanctions. ${ }^{1}$ Through exposure to sexual content on the Internet and online interactions with other individuals, adolescents acquire not only sexual information ${ }^{2}$ but also sexual gratification. ${ }^{3}$ The importance of understanding these behaviors lies in the fact that they are salient in how adolescents construct their sexual identities, exchange sex-related messages with others, ${ }^{4}$ have cybersex, ${ }^{5}$ and establish or maintain close relationships, both with known and unknown persons. ${ }^{6}$ Although evidence exists on how adolescents use the Internet for sexual purposes and engage in large scale sexually related online activities (SROA), it remains largely unknown who engages in SROA and to what extent.

It is known that adolescent sexuality is closely linked to peers and peer interaction. ${ }^{7}$ Based on Connolly and Goldberg's ${ }^{8}$ conception of how romantic relationships develop, the first erotic contact occurs between the ages of 14 and 16, a time when youth initially meet potential partners in the context of larger mixed-sex groups. Sexual activity becomes more prevalent between the ages of 17 and 20 when the focus of peer groups shifts to intimate dyads. Previous work has documented that the quality of peer relations and subsequent romantic relationships are closely related to a trust attachment that predicts subsequent onset of sexual activity. ${ }^{9}$ Specifically, establishing sexual relationships depends on the quality of child-caregiver attachment, such as the capacity to develop intense, enduring, preoccupying affections for one another regardless of either partner's sexual attractiveness, arousal, or sex. ${ }^{10}$ The quality of child-caregiver attachment, namely a child's experience with in/secure attachment bonding to adult caretakers, affects how adolescents subsequently relate to peers. ${ }^{11}$ Some youth might positively relate to others and experience positive affection and trust, while others respond with anger or hopelessness when approaching peers. ${ }^{12}$ Considering attachment as a potential moderator of sexual mating, we assume that the quality of an adolescent's attachment to his or her peers will play an important role in the acquisition of sexual experiences.

With the expansion of the Internet into adolescents' everyday lives, this new medium seems to provide an additional context for relationship formation, particularly for youth who experience relationship problems. ${ }^{13}$ The absence of social cues online leads users to express their "true" selves and to idealize their online partner, which in turn supports relationship formation as well as increases relationship

\footnotetext{
${ }^{1}$ Institute for Research on Children, Youth, and Family, Masaryk University, Brno, Czech Republic.

${ }^{2}$ Department of Family Sciences, Department of Psychology, University of Kentucky, Lexington, Kentucky.

${ }^{3}$ Faculty of Social Studies, Masaryk University, Brno, Czech Republic.

${ }^{4}$ Department of Management, Brno University of Technology, Brno, Czech Republic.
} 
satisfaction. ${ }^{14}$ This implies that trust attachment between peers may not be the only useful predictor in terms of understanding how and when sexual activities occur online. Specifically, thanks to the absence of social cues online, adolescents with a weak attachment to peers might overcome their difficulties in establishing close relationships and engage in SROA.

Using longitudinal data, the current study aimed to examine the extent to which the quality of peer attachment predicted SROA, while also considering previous offline sexual behaviors and pubertal status as known accelerators of sexual behaviors in adolescence. ${ }^{9}$ More generally, the focus was on understanding what predicted SROA, while also examining the same for offline sexual behaviors.

\section{Methods}

\section{Sample}

Confidential data were collected as part of the European Longitudinal Study of Pregnancy and Childhood (ELSPAC), which started in 1991. In the current paper, we focus on the Czech sample part of the ELSPAC, which included all the children with a residential address in the city of Brno, born between March (1991) and June (1992) - approximately 5,000 families. Starting in 1999, 883 children and their parents participated in broader psychological assessments when the children were $8,11,13,15$, and 17 years old. Due to attrition, the present study was based on 323 ethnically Czech youth (51.1\% girls) who remained part of the ELSPAC project until the age of 17. Respondents who agreed to participate were invited at the age of 15 (in 2006 and 2007) and 17 (in 2008 and 2009) to visit a research institute where they completed computer-administered questionnaires.

\section{Measures}

Peer attachment at the age of 15 . The quality of peer attachment was assessed using the Experienced Peer Relationships Scale developed by Širůček and Širůčková, using a 5 -point-Likert scale ranging from $1=$ "never" to $5=$ "always." ${ }^{15}$ The scale includes three subscales measuring trust (12 items; $\alpha=0.87, M=4.01, S D=0.56$ ), alienation (13 items; $\alpha=0.82, M=1.66, S D=0.41$ ), and ambivalence (six items; $\alpha=0.57, M=1.96, S D=0.53$ ) (See Appendix). Each scale score was computed by averaging the items; higher scores indicated greater attachment.

Pubertal status at the age of 15. Pubertal status was assessed by a single question asking adolescents to rate whether they perceived their bodies to be (1) like those of a child $(2.3 \%)$, (2) like those of an adolescent $(81.0 \%)$, or (3) like those of a woman/man $(16,7 \%)$; a higher score indicated more advanced pubertal status.

Offline sexual behaviors at the age of 15 . Offline sexual behaviors at the age of 15 were measured by five dichotomous items $(0=$ "no," $1=$ "yes") that asked youth whether they had ever (a) kissed, (b) necked (caressed or embraced), (c) petted (caressed intimate body parts), (d) had vaginal intercourse, or (e) had oral sex. A composite score was computed by summing all the items. A higher score indicated more sexual experiences $(\alpha=0.74, M=1.90, S D=1.40)$.
Table 1. Descriptive Statistics

\begin{tabular}{|c|c|c|c|c|}
\hline & $\mathrm{N}$ & $\%$ & $\mathrm{M}(\mathrm{SD})$ & Range \\
\hline Sex & 323 & 51.1 (girls) & & \\
\hline Peer attachment-trust & 323 & & $4.01(0.56)$ & $1-5$ \\
\hline $\begin{array}{l}\text { Peer attachment- } \\
\text { alienation }\end{array}$ & 323 & & $1.66(0.41)$ & $1-5$ \\
\hline $\begin{array}{l}\text { Peer attachment- } \\
\text { ambivalence }\end{array}$ & 323 & & $1.96(0.53)$ & $1-5$ \\
\hline Puberty & 306 & & $2.15(0.40)$ & $1-3$ \\
\hline $\begin{array}{l}\text { Offline sexual } \\
\text { behavior at the } \\
\text { age of } 15\end{array}$ & 316 & & $1.90(1.40)$ & $0-1$ \\
\hline SROA & 235 & & & \\
\hline $\begin{array}{l}\text { Offline sexual } \\
\text { behavior at the } \\
\text { age of } 17\end{array}$ & 276 & & & \\
\hline
\end{tabular}

SROA. At the age of 17, respondents were asked whether they had ever done any of the following nine behaviors: talked about sex with somebody known/somebody unknown; discussed their own sexual experiences with somebody known/somebody unknown; discussed somebody's sexual experiences with them, somebody known/somebody unknown; received erotic photos from somebody; sent their own erotic photos to somebody; and had "sex on the Internet." Although a 5-point Likert scale was used, ranging from $1=$ "never" to $5=$ "at least once a week," ratings were recoded into dichotomous items, namely $0=$ "no" and $1=$ "yes." This was due to the low frequencies of scores and their high positive skew. After summing scores from all the items, those who had online experiences were coded as 1 ; those with none were coded as 0 . A higher score indicated greater online experiences for sexual purposes. The scale had good internal consistency $(\alpha=0.83, M=2.67, S D=2.50)$.

Offline sexual behaviors at the age of 17 . Offline sexual behaviors at the age of 17 were measured by four dichotomous items $(0=$ "no," $1=$ "yes") asking youth whether they had ever (a) kissed, (b) petted or caressed someone's intimate body parts, (c) had oral sex, or (d) had vaginal intercourse. Due to space constraints in the questionnaire, necking was omitted. After summing scores from all the items, adolescents who experienced any such offline behaviors were coded as 1 , while those who lacked these experiences were coded as 0 . A higher score indicated more offline sexual behavior experiences $(\alpha=0.75, M=1.70, S D=1.18)$.

\section{Data analysis}

The data were analyzed using the PASW (SPSS) Statistics 18 software, where descriptive statistics (see Table 1) and two binary hierarchical binary logistic regressions were computed (see Table 2).

\section{Results}

At the age of 17, 21 respondents (7\%) reported no sexual experiences, 49 respondents (15\%) reported only offline experiences, 227 respondents (70\%) reported both offline and online experiences, and just eight respondents (3\%) engaged only in SROA. Two hierarchical binary logistic regression analyses were completed. Peer attachment (trust, alienation, 
Table 2. Hierarchical Logistic Regressions Predicting SROA and Offline Sexual Behaviors at the Age of 17

\begin{tabular}{|c|c|c|c|c|c|c|c|c|}
\hline & \multicolumn{4}{|c|}{ SROA experience $e^{\mathrm{a}, \mathrm{b}}$} & \multicolumn{4}{|c|}{ Offline sexual behaviors at the age of $17^{\mathrm{c}, \mathrm{d}}$} \\
\hline & $B(S E)$ & OR[95\% CI] & $R^{2 \mathrm{a}}$ & $\chi^{2}$ & $B(S E)$ & OR $(95 \% C I)$ & $R^{2 \mathrm{a}}$ & $\chi^{2}$ \\
\hline Step 1 & & & 0.07 & 11.44 & & & 0.05 & 9.30 \\
\hline PA trust & $0.69(0.30)^{*}$ & 1.99 [1.11-3.52] & & & $0.96(0.38)^{*}$ & $2.61[1.24-5.51]$ & & \\
\hline PA alienation & $1.35(0.52)^{* *}$ & 3.85 [1.40-10.55] & & & $0.92(0.66)$ & $2.51[0.69-9.06]$ & & \\
\hline PA ambivalence & $0.25(0.31)$ & $1.28[0.69-2.37]$ & & & $-0.50(0.42)$ & $0.61[0.27-1.40]$ & & \\
\hline Constant & $-4.23(1.74)^{*}$ & & & & $-2.10(2.17)$ & & & \\
\hline Step 2 & & & 0.21 & 7.95 & & & 0.41 & 2.60 \\
\hline PA trust & $0.54(0.32)$ & $1.71[0.91-3.23]$ & & & $0.74(0.51)$ & $2.09[0.77-5.65]$ & & \\
\hline PA alienation & $1.23(0.55)^{*}$ & 3.31 [1.17-9.35] & & & $0.55(0.79)$ & $1.73[0.38-8.12]$ & & \\
\hline PA ambivalence & $0.42(0.34)$ & $1.53[0.78-2.98]$ & & & $-0.28(0.48)$ & $0.76[0.30-1.94]$ & & \\
\hline Puberty & $1.03(0.45)^{*}$ & 2.08 [1.17-6.75] & & & $0.50(0.72)$ & $1.65[0.40-6.23]$ & & \\
\hline $\begin{array}{l}\text { Offline sexual behaviors } \\
\text { at the age of } 15\end{array}$ & $0.56(0.13)^{* * *}$ & $1.75[1.45-2.27]$ & & & $1.80(0.36)^{* * *}$ & $6.04[3.00-12.16]$ & & \\
\hline Constant & $-6.08(2.09)^{* * *}$ & & & & $-3.78(3.00)$ & & & \\
\hline
\end{tabular}

Notes. ${ }^{* * *} p<0.01 ; * * p<0.01 ; * p<0.05$.

$\mathrm{a}_{n=218}$; as the reference category was "No SROA experience" $(n=65) ;{ }^{\mathrm{c}} n=256$; ${ }^{\mathrm{d}}$ as the reference category was "No offline sexual behaviors at the age of $17^{\prime \prime}(n=27)$.

PA, peer attachment; B, unstandardized regression coefficient; SE, standard error; OR, odds ratio; $\mathrm{CI}$, confidence interval for OR; a, Nagelkerke; $\chi^{2}$, Hosler-Lemeshow fit index.

and ambivalence) were entered in the first step, and puberty as well as offline sexual behaviors at the age of 15 were entered in the second one. The first analysis predicted SROA using a comparison between youth who reported engaging in any SROA at the age of 17 and those who had no experiences with SROA. In the second analysis, which predicted offline sexual behaviors at the age of 17 , all youth who had any offline sexual experience at the age of 17 were compared with those who had no such experiences.

The initial model step showed that both trust and alienation attachment to peers significantly predicted SROA; only greater alienation from peers remained significant in the second step $(\mathrm{OR}=3.36, p<0.05)$ along with advanced pubertal status $(\mathrm{OR}=2.08, p<0.05)$ and previous offline sexual experiences $(\mathrm{OR}=1.75, p<0.001)$. In fact, youth who experienced alienation from peers were $330 \%$ more likely to engage in SROA. In the second model, predicting offline sexual behaviors at the age of 17 , peer trust was significant in the initial step. However, in the second step, only previous offline sexual experiences $(\mathrm{OR}=6.04, p<0.001)$ was statistically significant.

\section{Discussion}

Alienation attachment to peers, pubertal status, and prior offline sexual experiences predicted SROA in adolescents, while offline sexual behavior at the age of 17 was only predicted by prior sexual experiences. Thus, only for SROA, alienation was found to be an important correlate. With advancing age, adolescents are expected to use their emotional and cognitive capacity to establish and maintain relations with their peers and to acquire experience with erotic relationships. ${ }^{16,17}$ The Internet seems to help adolescents with poor peer relationships to overcome barriers and find someone with whom to interact sexually. This complements prior results, which showed a link between adolescents with poor relations to parents and establishing close online relationships. ${ }^{12}$

Advanced pubertal status also predicted SROA. A similar finding was revealed for passive use of the Internet for sexual purposes among adolescents, specifically for exposure to online sexually explicit materials. ${ }^{18}$ It may be that differences in the timing of pubertal development lead those with advanced pubertal status to turn to the Internet to discuss sexual issues, as their less developed offline peers might lack interest in sexuality. But it is also possible that Internet use for sexual purposes has generally become an ordinary part of adolescent development, particularly for youth with an advanced pubertal status.

Prior offline sexual experiences seem generally to be an important characteristic of those who engaged in SROA and were sexually active at the age of 17 . However, a lack of data on SROA at younger ages prevents a conclusion as to whether SROA is an outcome of prior offline sexual experiences or vice versa.

This longitudinal study has several limitations that need to be mentioned. First, a single-item measure of puberty was used. Further, small sample sizes limited the use of multinomial regressions, which would have allowed the analysis of differences in predictors of SROA and offline sexual behaviors. Findings are also limited in that they cannot be readily generalized given the sample. This study was conducted on a sample of ethnically homogenous Czech youth. ${ }^{19}$ In addition, it is important to note that data were collected confidentially, which might have affected how respondents rated items. In turn, this might also have impacted study findings. Despite these limitations, this study's findings indicate that the Internet provides an additional context of acquiring sexual experiences in adolescence. To what extent youth with alienation attachment and advanced pubertal status profit from SROA seems to be a crucial question for future research.

\section{Acknowledgments}

This work was supported by a Fulbright-Masaryk Distinguished Chair fellowship to the second author (Fall, 2010) and by the Faculty of Social Studies, Masaryk University to the remaining authors. The authors also acknowledge the support of the Czech Science Foundation (GAP407/11/0585), the VITOVIN project (CZ.1.07/2.3.00/20.0184), which is 
co-financed by the European Social Fund, and the state budget of the Czech Republic.

\section{Author Disclosure Statement}

No competing financial interests exist.

\section{References}

1. Daneback K, Ross MW. The complexity of Internet sexuality. Advances in Psychosomatic Medicine 2011; 31:121-134.

2. Suzuki LK, Calzo JP. The search for peer advice in cyberspace: an examination of online teen bulletin boards about health and sexuality. Applied Developmental Psychology 2004; 25:685-698.

3. Boies SC. University students' uses of and reactions to online sexual information and entertainment: links to online and offline sexual behaviour. Canadian Journal of Human Sexuality 2002; 11:77-89.

4. Smahel D, Subrahmanyam K. "Any girls want to chat press 911": Partner selection in monitored and unmonitored teen chat rooms. CyberPsychology \& Behavior 2007; 10:346-353.

5. Šmahel D. (2003) Psychologie a internet: děti dospělými, dospělí dětmi [Psychology and Internet: Children adults, adults children]. Praha: Triton.

6. Wolak J, Mitchell K, Finkelhor, D. Close online relationships in a national sample of adolescents. Adolescence 2002; 37: 141-155.

7. Brown BB, Feiring C, Furman, W. (1999) Missing the love boat: why researchers have shied away from adolescent romance. In Furman W, Brown, BB, Feiring C, eds. The development of romantic relationships in adolescence. New York: Cambridge University Press, pp. 1-16.

8. Connolly J, Goldberg A. (1999) Romantic relationships in adolescence: the role of friends and peers in their emergence and development. In Furman W, Brown BB, Feiring C, eds. The development of romantic relationships in adolescence. New York: Cambridge University Press, pp. 266-290.

9. Crockett LJ, Bingham CR, Chopak JS, et al. Timing of first sexual intercourse: the role of social control, social learning, and problem behavior. Journal of Youth \& Adolescence 1996; 25:89-111.
10. Diamond LM. Emerging perspectives on distinctions between romantic love and sexual desire. Current Directions in Psychological Science 2004; 13:116-119.

11. Allen JP, Land D. Attachment in adolescence. In Cassidy J, Shaver $\mathrm{P}$, eds. Handbook of attachment theory and research. New York: Guilford Press, pp. 319-335.

12. Armsden GC, Greenberg MT. The inventory of parent and peer attachment: individual differences and their relationship to psychological well-being in adolescence. Journal of Youth \& Adolescence 1987; 16:427-454.

13. Wolak J, Mitchell KJ, Finkelhor D. Escaping or connecting? Characteristics of youth who form close online relationships. Journal of Adolescence 2003; 26:105-119.

14. Bargh JA, McKenna KYA. The Internet and social life. Annual Review of Psychology 2004; 55:573-590.

15. Širůček J, Širůčková M. (2008) Experienced relationships with peers. In Ježek S, Lacinová L, eds. Fifteen-year-olds in Brno: a slice of longitudinal self-reports. Brno: Masaryk University, pp. 13-18.

16. Havinghurst RJ. (1948) Developmental tasks and education. New York: McKay.

17. Macek P. (2003) Adolescence: psychologické a sociální charakteristiky dospívajících. [Adolescence: psychological and social characteristics of adolescents]. Praha: Portál.

18. Peter J, Valkenburg PM. Adolescents' exposure to sexually explicit material on the Internet. Communication Research 2006; 33:178-204.

19. CZSO. (2011) Preliminary results of the census 2011. Available at www.czso.cz/eng/redakce.nsf/i/summary_data_on_the_ czech_republic (accessed January 10, 2012).

Address correspondence to: Anna Ševčíková Institute of Children, Youth and Family Research Faculty of Social Studies Masaryk University Joštova 10 Brno 60200 Czech Republic

E-mail: asevciko@fss.muni.cz

\section{Appendix}

\section{Peer Attachment}

\section{Peer attachment-trust}

1. They are concerned about what I do.

2. They take me seriously.

3. They understand me.

4. Their opinions are important to me.

5. I make time for them when they need it.

6. I would do anything for them.

7. My friends respect my feelings.

8. I can open up to them.

9. They can be honest with me.

10. They are with me when I feel lonely.
11. I tell them the truth.

12. They listen to me when I need it.

Peer attachment-alienation

1. They try to decide for me.

2. They bad-mouth me.

3. They lie to me.

4. They express disapproval of my behavior.

5. If I ask them for anything, they make excuse.

6. I bad-mouth them.

7. We argue with each other.

8. They call me names. 
9. They refuse me.

10. When they organize something, they do not let me know about it.

11. They make fun of me.

12. They ignore me when I suggest something.

13. They react aggressively if I tell them something they do not like.

\section{Peer attachment-ambivalence}

1. I conform to them.

2. I am afraid I could lose them.

3. I am afraid they will betray me.

4. I am afraid they are ashamed of me.

5. They are better than me in every way.

6. I am ashamed in front of them. 
This article has been cited by:

1. Danielle M. Crimmins, Kathryn C. Seigfried-Spellar. 2014. Peer attachment, sexual experiences, and risky online behaviors as predictors of sexting behaviors among undergraduate students. Computers in Human Bebavior 32, 268-275. [CrossRef] 